\title{
LOS CONCEPTOS SALUD Y ENFERMEDAD CONTENIDOS EN EL CORÁN
}

\section{Lourdes Rubio Rico*, María Ferrater Cubells**}

*Diplomada en Enfermería. Licenciada en humanidades y doctoranda del programa Estudis Culturals M editerranis de la U niversitat Rovira i Virgili de Tarragona. Enfermera H ospital U niversitari Joan XXII de Tarragona. Profesora Asociada de la Escuela U niversitaria de Enfermería de la U niversitat Rovira i Virgili de Tarragona **Diplomada en Enfermería. Profesora titular de la Escuela U niversitaria de Enfermería de la U niversitat Rovira i Virgili de Tarragona.

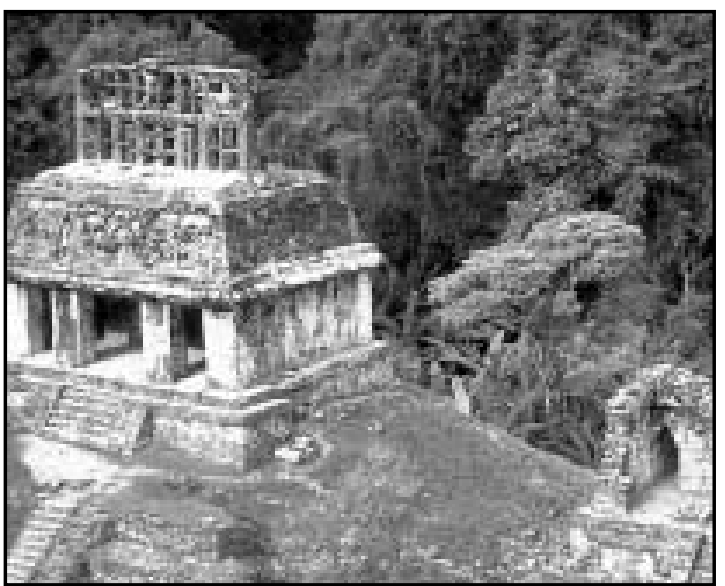

CONCEPTS OF HEALTH AND ILLNESS IN THE KORAN

\section{SUMMARY}

$\mathrm{T}$ The inter-cultural concept as a legal response to the fact of a multicultural society equally entitles rights and commitments accepting no difference in cultures claiming at the same time the right to be different. In this context, health professionals feel the need to approach cultural concepts different from their own that allow them to understand the essence of new interacting cultures. This sort of approaching, according to Leninger (i), must take into consideration the point of view of any individual and try to integrate in a system of professional knowledge as to be the core for health interventions coherent with cultural modes.

The Islamic theological system, through the Koran, soaks the whole life of the Islamic people cultures. The terms: health and illness are frequent in the Islamic religious texts, among them the
Koran. For those reasons and the above mentioned ones, the Islamic sacred texts in general, and the Koran in particular are very useful to health professionals in order to build up the emic vision stated by Leninger.

Analysis and exegesis of the Koran according to the above mentioned terms are presented here.

Key Words: Trans-cultural nursing, Islam, Koran, holism, spiritualism, support

\section{RESUMEN}

T a interculturalidad, como respuesta normativa al hecho multicultural, reconoce igualmente derechos y obligaciones sin atender a diferencias culturales y reivindica, con ello, la igualdad en el derecho a ser diferentes. En este contexto, los profesionales de la salud se ven en la necesidad de aproximarse a conceptos culturales ajenos que permitan captar la esencia de las nuevas culturas en interacción. Esta aproximación, según la teoría de Leininger (Leininger 1991), debe incorporar el punto de vista del sujeto e integrarse en un sistema de conocimiento profesional para servir de base a intervenciones de salud coherentes con los modos culturales.

El sistema teológico islámico, a través del Corán, impregna la totalidad de la vida de las personas de cultura islámica. Los términos salud y enfermedad son frecuentes en los textos religiosos islámicos, entre ellos el Corán. Por esta razón y las esgrimidas anteriormente, los textos sagrados islámicos, en general, y el Corán, en particular, son útiles a los profesionales de la salud para construir la visión emic propugnada por Leininger. 
Presentamos, desde la mirada del profesional de la salud, un análisis y exégesis del Corán atendiendo a los términos mencionados.

Palabras clave: enfermería transcultural, Islam, Corán, holismo, espiritualidad, solidaridad.

\section{INTRODUCCIÓN:}

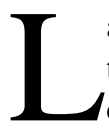
a globalización ha dado lugar a la multiculturalidad, término descriptivo, factual y contrastable que define la coexistencia de diferentes culturas en una misma sociedad. La interculturalidad, como respuesta normativa al hecho multicultural, reconoce igualmente derechos y obligaciones sin atender a diferencias culturales y reivindica, con ello, la igualdad en el derecho a ser diferentes. En este contexto, los profesionales de la salud se ven en la necesidad de aproximarse a conceptos culturales ajenos que permitan captar la esencia de las nuevas culturas en interacción. Esta aproximación, según la teoría de Leininger (Leininger 1991), debe incorporar el punto de vista del sujeto e integrarse en un sistema de conocimiento profesional para servir de base a intervenciones de salud coherentes con los modos culturales.

El sistema teológico islámico, a través del Corán, impregna la totalidad de la vida de las personas de cultura islámica puesto que además de ser presentado como un texto divino por sus orígenes -bajado del cielo- y su tema fundamental -el papel de Dios, Al-lá, en el mundo y en la historia humana-, es también un libro humano que se ocupa de los aspectos fundamentales que rigen la vida terrenal de hombres y mujeres del pasado, del presente y del futuro (Epalza de 2001). Los términos salud y enfermedad son frecuentes en los textos religiosos islámicos, entre ellos el Corán. Por esta razón y las esgrimidas anteriormente, los textos sagrados islámicos, en general, y el Coran, en particular, son útiles a los profesionales de la salud para construir la visión emic propugnada por Leininger.

\section{OBJETIVOS:}

- Definir los conceptos salud y enfermedad contenidos en el Corán

- Determinar las implicaciones prácticas en el cuidado y la atención a la salud que derivan direc- tamente de los conceptos salud y enfermedad contenidos en el Corán

\section{MATERIAL Y MÉTODOS:}

Lectura, análisis y exégesis del texto coránico atendiendo a los conceptos salud y enfermedad

\section{RESULTADOS:}

El concepto de salud contenido en el Corán surgido de la lectura y análisis del texto se construye por definición y por oposición de sus contrarios o complementarios. En el primer caso, la definición del término nos remite al dominio de la espiritualidad. La salud atañe al espíritu, al dominio de las creencias y los valores del hombre. En una existencia terrenal que viene determinada por la divinidad, tanto en sus aspectos puramente físicos o naturales como en los existenciales:

Y la tierra, la hemos extendido, y colocamos en ella firmes montañas, y hemos hecho crecer en ella de todo y en forma equilibrada, y hemos puesto en ella medios de subsistencia para vosotros [los hombres], y para todos aquellos [seres vivos] cuyo sustento no depende de vosotros.

Pues nada existe que no tenga en Nosotros su origen; y no hacemos descender nada si no es con arreglo a una medida precisa.

Y enviamos los vientos para fertilizar [las plantas], y hacemos caer el agua del cielo y de ella os damos de beber, y no sois vosotros quienes disponéis de su fuente, pues, iciertamente, somos Nosotros -sólo Nosotros-quienes damos la vida y damos la muerte, y sólo Nosotros permaneceremos cuando todo lo demás haya desaparecido!

Y conocemos bien [los corazones y las obras de todos los seres humanos -tanto] de aquellos que vinieron antes de nosotros como de los que vendrán después de vosotros

Al-Hichr (15:19-24)

la relación que el hombre establece con la divinidad se sitúa en un nivel prioritario y rige la mayoría de las acciones y pensamientos humanos. En este contexto, la salud, que adquiere una dimensión espiritual, proviene de la revelación divina:

¡Oh Gentes! Os ha llegado ahora una exhortación de vuestro Sustentador, una cura para todo 
[mal] que pueda haber en los corazones de los hombres, una guía y una misericordia para todos los que creen [en Él]

Iunus (10:57)

Así hacemos descender gradualmente por medio de este Qur'án todo aquello que da salud [al espíritu] y es una misericordia para quienes creen [en Nosotros], mientras que a los malhechores no hace más que aumentar su perdición

Al-Isra (17: 82)

[...] Di: "Para todos los que han llegado a creer, esta [escritura divina] es una guía y fuente de salud; pero para los que aún no creen, en sus oídos hay sordera, y por eso siguen a oscuras respecto de ella: [son como gentes que] están siendo llamadas desde demasiado lejos

Fussilat (41:44)

Análogamente, la mención a la enfermedad está condicionada -en gran parte, aunque no siempre- a la vertiente espiritual de la existencia humana. El concepto de enfermedad se construye desde la relación establecida entre el hombre y su fe. La enfermedad se describe como aquella situación de impermeabilidad al mensaje divino y negación de la verdad revelada al profeta. La concepción de la enfermedad ligada a la fe configura una anatomía de la espiritualidad que confiere especial protagonismo al corazón como órgano donde se asientan la fe, la incredulidad, los sentimientos o la voluntad; generando gran número de expresiones que hablan de su enfermedad, dureza o insensibilidad. En un segundo plano, son los sentidos quienes, de manera similar a como ocurre en la naturaleza, se erigen en instrumentos de conocimiento, en este caso, espiritual:

Pero a aquellos en cuyos corazones hay enfermedad, cada nuevo mensaje tan sólo añade otro [elemento de] incredulidad a la incredulidad que ya albergan, y mueren negándose [aún] a aceptar la verdad.

Al-Tauba (124:125)

$Y$ ciertamente hemos destinado al infierno a muchos seres invisibles y hombres que tienen corazones con los que no comprenden la verdad, ojos con los que no ven y oídos con los que no oyen. Son como el ganado ique va! Son aún menos conscientes del camino recto jellos, precisamente, son los [realmente] inconscientes!

Al-Aaraf (7:179)

En un contexto en que la vida terrenal constituye sólo una pequeña parte de la existencia humana, la salud física es irrelevante y sólo se concibe desde su relación con la salud espiritual. De hecho, la salud física -en positivo- se menciona en una sola ocasión, aunque mediatizada por el hecho espiritual:

[En cuanto a mí, sé que] esos [falsos dioses] son ciertamente mis enemigos, [y que nadie me presta auxilio] salvo el Sustentador de todos los mundos, que me ha creado y es quién me guía, y es quien me da de comer y de beber, y cuando caigo enfermo, es Él quien me devuelve la salud y quien me hará morir y luego me devolverá la vida

Ash-Shuaara (26:77-81)

En cuanto a la enfermedad, que ya hemos visto que se expresaba como concerniente al ámbito espiritual, suele presentarse también desde su expresión física y terrenal, aunque nunca disociada del hecho espiritual al que se une a través de su relación con los preceptos del Islam y, tal como se verá posteriormente, a través de su significado. La enfermedad física, en su relación con los preceptos que se exigen al creyente, se nos muestra como una circunstancia excepcional, de extrema dureza que excusa al creyente de todas sus obligaciones como tal, exceptuando la oración. Así pues, la expresión Pero, si alguno de vosotros está enfermo suele repetirse acompañada de la dispensa en la realización del ayuno del Ramadán, el peregrinaje a la Meca, y las abluciones previas a la oración; que son circunstancias en la vida del creyente que exigen una cierta capacidad física. Por otra parte, aunque sin ser citada explícitamente, la necesidad extrema entre la que se incluye la enfermedad, según interpreta Asad (Asad 2001), también exime al musulmán de las prohibiciones islámicas.

[...] Pero quien se vea empujado [a usar lo prohibido] por necesidad extrema y no con ánimo de transgredir, ciertamente, dios es indulgente, 
dispensador de gracia.

Al-Ma'ida (5:3)

Por lo que respecta al sentido de la enfermedad, es frecuente la mención genérica a la adversidad como prueba de fe, siendo la paciencia y la perseverancia en la oración las virtudes que confirman la fe del creyente en las situaciones de dificultad, entre las que, por supuesto, se encuentra la enfermedad:

¡Oh vosotros que habéis llegado a creer! Buscad ayuda en la paciencia y la oración: pues, ciertamente, Dios está con los que son pacientes en la adversidad

Al-Baqara (2:153)

Aunque como refuerzo a la mención genérica del papel de la adversidad en la vida terrenal del creyente, el texto ofrece, además, una cita explícita donde se concretan las pruebas terrenales por las que habrá de pasar el creyente:

$Y$ ciertamente os pondremos a prueba por medio del peligro, del hambre, de la pérdida de bienes, de vidas y de frutos [del trabajo]. Pero da buenas nuevas a los que son pacientes en la adversidad, que cuando les sucede una desgracia, dicen: "En verdad, de dios somos y, ciertamente, a Él hemos de volver"

Al-Baqara (2:155-156)

Situados, pues, en el continuo existencial del hombre donde la existencia terrenal viene definida por la temporalidad; la enfermedad física es importante $-\mathrm{y}$ así se reconoce en el texto- por el sufrimiento y la incapacidad que genera, aunque se trata de una experiencia pasajera inscrita en la circunstancia vital terrestre y siempre al servicio de la causa espiritual, ya sea como dotadora de sentido, ya sea como pequeño contratiempo en el ejercicio de la espiritualidad del creyente. La enfermedad física es útil al doliente en tanto en cuanto le permite ejercitarse en la superación a través del ejercicio de la paciencia, beneficiando también a su entorno al permitirle la práctica de la solidaridad, que para la religión islámica constituye una obligación institucionalizada a través del Sakat, el impuesto de purificación de la riqueza:
[Todos vosotros, Oh creyentes, sois hermanos: así pues:] no es motivo de reproche que el ciego, el cojo o el enfermo [acepten limosna del que está sano], ni que vosotros comáis [de lo que otros os ofrezcan, ya sea comida procedente] de vuestras casas, o de casa de vuestros padres, o de vuestras madres, o de vuestros hermanos, o de vuestras hermanas, o de vuestros tíos paternos, o de vuestras tías paternas, o de vuestros tíos maternos, o de vuestras tías maternas, o de aquellas [casas] cuyas llaves tenéis a vuestro cargo o [de casa] de algún amigo vuestro [...]

An-Nur (24:61)

Afectando por igual a los términos salud y enfermedad aparece en los textos seleccionados, y en el resto del libro, una suerte de determinismo teológico que aparentemente afecta a la totalidad de acontecimientos y decisiones que afectan a la vida humana, dejando al hombre impotente ante el destino trazado de antemano por la divinidad. La realidad, pero, es que el texto, aún a riesgo de pecar de cierta incoherencia interna, reserva una parcela de autonomía humana que libera al hombre del intervencionismo divino y lo responsabiliza de sus propias actuaciones y consecuencias. La responsabilidad del hombre ante su propio destino se concentra en la elección y el ejercicio de la fe; decisión humana que una vez tomada ha de determinar, por consiguiente, una serie de efectos divinos revestidos de determinismo que son, en realidad, resultado de la libertad humana y que han de afectar a algunos aspectos concretos de la vida terrenal -entre ellos la vivencia de la enfermedad- y a la totalidad de la vida humana después de la muerte:

[refiriendose a los judíos] [...] Si hubiéran dicho: "Oímos y obedecemos", y "Escucha[-nos] y ten paciencia con nosotros", hubiera sido mejor para ellos y más correcto: pero Dios les ha rechazado por negarse a reconocer la verdad-porque poco es aquello en lo que creen.

An-Nisa (4:46)

Y recordad [siempre] las bendiciones que Dios os ha concedido y el solemne compromiso por el que os vinculó a Sí cuando dijisteis: Oímos y obedecemos" [...]

Al-Ma'ida (5:7) 
En un plano más concreto, la ceguera y la cojera son las enfermedades que suelen citarse como excusa en el cumplimiento de los preceptos religiosos, aunque, con el mismo objeto, también es frecuente la mención genérica a la enfermedad. La vejez aparece como una situación de declive físico e intelectual o incluso de incapacidad extrema semejante a la del recién nacido:

Dios os ha creado, y en su momento os hará morir; y muchos de vosotros quedan reducidos en la vejez a un estado de lo más abyecto, en el que dejan de saber lo que una vez tan bien supieron

An-nahl (16:70)

y es utilizada nuevamente como pretexto para insistir en el valor de la solidaridad, desplegada ahora desde el ámbito familiar, aunque de alcance comunitario, porque la benevolencia de trato que se recomienda a los hijos para con sus padres responde con justicia al cuidado previo de éstos para con ellos, un cuidado que además de contribuir al desarrollo físico e intelectual, ha contribuido, por medio de la educación, al crecimiento moral del buen musulmán y su comunidad; un cuidado que, finalmente, en virtud de esta conexión vital entre materia espíritu, se deposita en manos de Dios

\section{[...] Y haced el bien [a vuestros padres]. Si a} uno de ellos, o a ambos, les llega la vejez estando contigo, jamás les digas “;Uff! Ni les riñas, sino háblales con respeto, y extiende sobre ellos con humildad las alas de tu benevolencia, y di: ;Oh sustentador mío; iApiádate de ellos, como ellos cuidaron de mí y me educaron siendo niño!"

Al-Isra (17:24)

\section{CONCLUSIONES Y DISCUSIÓN:}

Los conceptos salud y enfermedad contenidos en el texto coránico se refieren primariamente a la dimensión espiritual del ser humano y secundariamente aparecen asociados a aspectos físicos y terrenales de la existencia, en virtud del reconocimiento de la naturaleza humana como un sistema constituido por diversos aspectos íntimamente relacionados, en un individuo que a su vez se relaciona con el entorno próximo de la familia, la comunidad, el medio físico inmediato y el universo en general.
La emergencia de la solidaridad como valor desplegado a través de la familia y la comunidad al igual que la consideración integral e integrada del ser humano, condicionan la práctica de la atención a la salud desde una determinada perspectiva, aquella que considera necesariamente la promoción de la solidaridad desde nuevos límites -más allá de la familia nuclear- y la concepción del ser humano más allá de la estricta consideración como ser bio-psico-social, entendido también como ser espiritual integrado en un entorno íntimo, social y natural formando parte de la misma esencia sagrada. La promoción del ejercicio de la solidaridad como un valor de salud útil para el doliente y su entorno, y la consideración del ser humano como un todo integrado en un entorno igualmente valioso, constituyen elementos del cuidado que se convierten en marca de excelencia de los cuidados transculturales aplicados a pacientes islámicos.

La primera reflexión que surge a raíz de los resultados obliga a cuestionarse la distancia cultural entre los valores propios de la cultura judeocristiana y los valores surgidos del análisis de los resultados -solidaridad y holismo-, para seguidamente plantearse la mediterraneidad de determinados valores, o lo que es lo mismo, el alcance metaislámico de la solidaridad y el holismo aplicados al cuidado de la salud. El texto islámico analizado surge en la misma zona donde nacieron las otras dos grandes religiones monoteístas, reconoce en el cristianismo y el judaísmo una herencia profética común, comparte con ellos la idea de un Dios único y creador y participa, junto a las otras dos religiones, de la misma tradición básica nacida de la alianza de Dios con Abraham; por todo ello no son de extrañar las coincidencias en el mensaje religioso monoteísta, expresadas a través de la promoción de la solidaridad entre la comunidad y la íntima conexión entre las facetas física y espiritual del ser humano, que, a partir de este análisis, se revelan fundamentalmente mediterráneas y no exclusivamente islámicas. La mediterraneidad de los valores citados encierra un nuevo valor, aquel que permite reconocernos en una identidad ajena para desencadenar un proceso de acercamiento intercultural y beneficiarnos de nuevos recursos de salud procedentes del intercambio entre culturas.

No corresponde aquí entrar en valoraciones descontextualizadas sobre el hecho religioso como 


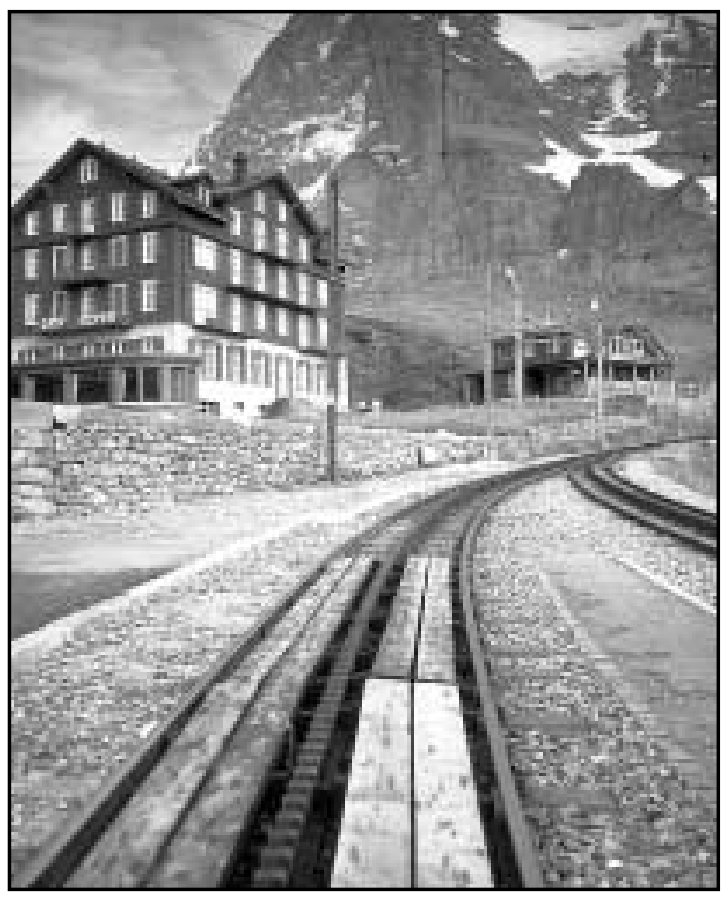

elemento de control humano. La realidad es la que es y el hecho religioso nos importa por su penetración en la vida de las personas y por sus efectos concretos sobre la existencia humana y la experiencia de enfermar. Aún así, otros textos islámicos, de clara raíz teológica pero tratando aspectos humanos como los hadiths, que relatan los hechos del profeta en situaciones concretas de la vida terrenal y sirven igualmente como guía vital a la comunidad islámica, pueden sernos útiles para desvelar aspectos más terrenales igualmente referidos al concepto de salud y a la experiencia de enfermar, es por ello que a partir de esta primera aproximación a los significados de la salud y la enfermedad en el contexto cultural islámico, el análisis de los hadiths surge como una nueva necesidad para completar los significados de la salud en el contexto cultural mencionado.

En un momento en que la atención a la salud a menudo se percibe disgregada y con un excesivo predominio de la vertiente biomédica, la apuesta holista en el cuidado a la salud ofrece la oportunidad de mejorar la satisfacción de usuarios y cuidadores. A los usuarios porque insiste en considerarlos como personas enteras y a los cuidadores porque los reafirma en un rol profesional que los dis- tingue de otros profesionales de la salud y los hace exclusivos para el receptor de cuidados. La conexión entre el cuerpo físico y la espiritualidad del ser humano -con independencia del hecho religioso- es una realidad reconocida por la Organización Mundial de Salud (WHO 1996) y por la ciencia enfermera (Rassool 2000) que debe ser promocionada desde la concepción de la espiritualidad como recurso de salud útil en la experiencia de enfermar.

El sufrimiento con sentido, la enfermedad como experiencia de crecimiento no pueden ser, por supuesto, óbices para el reconocimiento del dolor-del tipo que sea- y el alivio del doliente y su entorno; aunque encontrar sentido al sufrimiento puede -y debe- proporcionar al cuidador elementos para acercarse a ese sufrir ajeno con una nueva mirada, una nueva mirada que puede extenderse y demostrarse útil en nuevas situaciones. La religiosidad no es el único contenido de la espiritualidad. La espiritualidad es una realidad humana que a menudo se manifiesta más allá del hecho religioso, aunque la naturaleza espiritual de las diferentes manifestaciones de la espiritualidad permite intercambiar experiencias y soluciones. Es aquí donde tiene cabida el reconocimiento del sentido de la adversidad y el sufrimiento, como recurso de salud útil en el acercamiento profesional a la experiencia de enfermar. Saber que el sufrimiento puede tener sentido, ayuda a soportarlo. Conocer el sentido que otros han dado a este sufrimiento puede ayudarnos a encontrarle nuestro propio sentido. La experiencia de enfermar no concluye nunca en un balance absoluto, y a pesar de la dureza del camino, el transcurrir de la experiencia -inevitable, por otra parte- es en sí una riqueza que abre el ser humano a nuevos descubrimientos que, de no ser así, no viviría.

El sufrimiento del otro es, para los profesionales de la salud, un espectáculo cotidiano, conmovedor, que constituye razón de ser profesional, que moviliza energía y conocimiento en aras de su solución. La experiencia de enfermar no es una experiencia exclusivamente física como algunos podrían pensar. La experiencia de enfermar es física, económica, psicológica, moral, social... es una experiencia poliédrica que a menudo sobrepasa la capacidad del entono inmediato para darle respuesta. La experiencia de enfermar se conforma en su 
transcurrir como una situación compleja que se expresa externamente de manera parcial y críptica, velando significados y mostrando apariencias. La experiencia de enfermar demanda en los profesionales una actitud atenta a los sentidos ocultos, capaz de romper el círculo vicioso del prejuicio y la superficialidad que no hacen más que incrementar el malestar del que sufre. El esfuerzo por comprender al otro no es nunca un esfuerzo estéril. El paso profesional de la mera observación distante cuando no crítica- a la implicación activa en la interpretación de los significados del otro, contribuye a unos cuidados más eficaces y más satisfactorios, y acumula en el profesional un beneficio que se arrastra día a día en forma de nuevos saberes, mayor respeto y valoración del otro.

\section{BIBLIOGRAFÍA}

- Asad, M. (2001) El mensaje del Qur'an. Junta Islámica, Córdoba.

- Epalza de, M. (2001) L'Alcorà. Proa, Barcelona

- Kleinman, A. y Benson, P. (2004) La vida moral de los que sufren enfermedad y el fracaso existencial de la medicina. Monografias Humanitas 2, 17-26.

- Leininger, M. M. (1991) Ethnonursing: A research method with enablers to study the theory of culture care. Culture care diversity and university: a theory of nursing. National League for Nursing Press, New York pp. 73-117.

- Rassool, G. H. (2000) The crescend and Islam: healing, nursing and the espiritual dimension. Some considerations towards an understanding of the Islamic perspectives on caring. Journal of Advanced Nursing, 32(6), 1476-1484.

- World Health Organization,Regional Office for the Eastern Mediterranean (1996) Health promotion through Islamic lifestyles: the Amman Declaration. World Health Organization, Alexandria, Egypt. Disponible en: www.emro. who.int/Publications/HealthEdReligion/AmmanDeclaration/

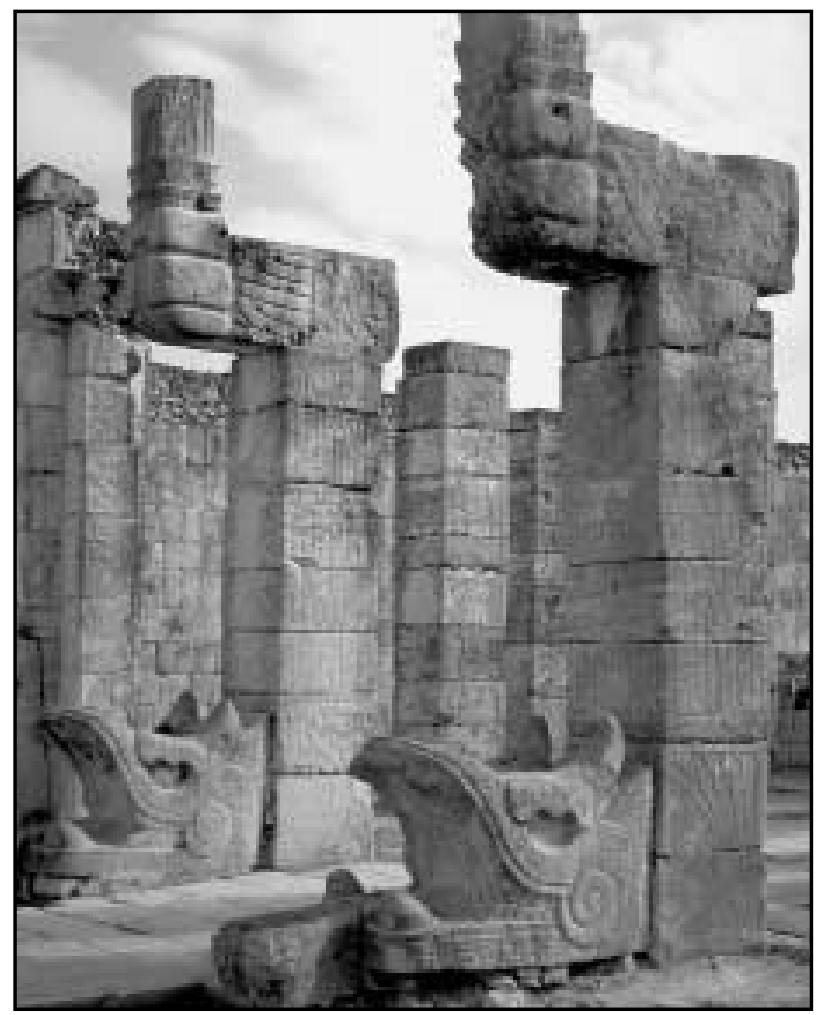

